book, 'Schlaf und 'Traum,' and keeping a record of his dreams, whenever he had a dim idea that he had seen an object or had a thought before, he generally found that his dreams had contained something like it. But he overlooks the consideration that the dream, as well as the feeling, might have been a case of inherited recollection.

C. L. F.

Baltimore, March 24.

The reproduction of Clathrulina elegans.

An article with this title (Science, iii. 303), by Dr. Stokes, contains two errors, to which his attention is courteously directed, and which are evidently founded upon an incorrect abstract of Miss Foulke's paper. Dr. Stokes says Miss Foulke's statements are "apparently confined chiefly to a process by quadruple subdivision of the body into uniflagellate organisms as observed by herself, with allusions to three additional processes as observed by others." Of the four processes described by the writer, three were first described by her, the fourth being that described by Cienkowski. Again : in the last paragraph is an error resulting from the position of the quotationmarks, which would seem to classify one of the writer's observations with those of Dr. Stokes. Colonies are also formed by the Actinophrys form of young, and the dissemination of the species is carried on as well by the uniflagellate as by the bi-flagellate organisms. 'These observations should teach us how varied may be the forms assumed by one animal.

SARA GWENDOLEN FoulKe.

\section{WHAT IS A LIBERAL EDUCATION?}

I po not intend, in the present paper, to enter upon the disputed question between the advocates of classical culture on the one hand, and those of scientific training on the other; because it seems to me that the line on which the two parties divide is not that which really divides the thought of the day. If we look closely into the case, we shall see that the objects of a higher education may be divided into three classes, instead of the two familiar ones of liberal and professional. In fact, what we commonly call a liberal education should, I think, have two separate objects. With the idea of a professional education we are all familiar: it is that which enables the possessor to pursue with advantage some wealthproducing specialty. Although, in accordance with well-known economic principles, it is designed to make the individual useful to his fellow-men, the ultimate object in view is the gaining of a livelihood by the individual himself. On the other hand, the object had in view in what is commonly known as culture, is not the mere gaining of a livelihood, but the acquisition of those ideas, and the training of those powers, which conduce to the happiness of the individual. From this point of view, culture may be considered an end unto itself.

The third object which we have to consider is only beginning to receive recognition in the eyes of the public. It is the general usefulness of the individual, not merely to himself and to those with whom he stands in business relations, but to society at large. Modern thought and investigation lead to the conclusion, that man himself, the institutions under which he lives, and the conditions which surround him, are subject to slow, progressive changes ; and that it depends very largely on the policy of each generation of mankind whether these changes shall be in the way of improvement or retrogression. During the next fifty years all of us will have passed from the stage of active life, and the course of events will be very largely directed by men who are still unborn. The happiness of those men is, from the widest philanthropic point of view, just as important as the happiness of those who now inhabit the earth; and, in the light of modern science, we now see that that happiness depends very largely upon our own actions. We thus have opened out to us an interest and a field of solicitude in which we need the best thought of the time. The question is, what form of education and training will best fit the now rising generation for the duty of improving the condition of the generation to follow it?

Let it be understood that we are now speaking, not of the education of the masses, but of that higher education which is necessarily confined to a small minority. So far as I am aware, that fraction of the male population which receives a college education is not far from one per cent. To that comparatively small body we must look for the power which is to direct the society of the future, and by their acts to promote the well or ill being of the coming generation. Our duty to that generation is to so use and train this select body as to be of most benefit to the men of the future. What is the training required? I reply by saying that I know nothing better for this end than a wide and liberal training in the scientific spirit and the scientific method. The technicalities of science are not the first object; and, so far as they are introduced, it is only as media through which we may imbue the mind with certain general and abstract ideas. If called. upon to define the scientific spirit, I should say that it was the love of truth for its own sake. This definition carries with it the idea of a love of exactitude, - the more exact we are, the nearer we are to the truth. It carries with it a certain independence of authority; because, although an adherence to authoritative propositions taught us by our ancestors, and which we regard as true, may, in a certain sense, be 